\title{
Matrix Isolation FTIR Spectroscopic and Theoretical Study of Dimethyl Sulfite
}

\author{
Ana Borba, ${ }^{\dagger}$ Andrea Gómez-Zavaglia, ${ }^{\dagger}$, Pedro N. N. L. Simões, $^{\S}$ and Rui Fausto ${ }^{*}, \dagger$ \\ Department of Chemistry, University of Coimbra, P-3004-535 Coimbra, Portugal, Facultad de Farmacia y \\ Bioquímica, Universidad de Buenos Aires, RA-1113 Buenos Aires, Argentina, and Department of Chemical \\ Engineering, University of Coimbra, P-3030-290 Coimbra, Portugal
}

Received: January 3, 2005; In Final Form: February 16, 2005

\begin{abstract}
The preferred conformations of dimethyl sulfite and their vibrational spectra were studied by matrix-isolation Fourier transform infrared spectroscopy and theoretical methods (density functional theory (DFT) and MollerPlesset (MP2), with basis sets of different sizes, including the quadruple- $\zeta$, aug-cc-pVQZ basis). Five minima were found at these levels of theory. At the MP2/6-31++G(d,p) and DFT/B3LYP/aug-cc-pVQPZ levels, the GG conformer (where the $\mathrm{O}-\mathrm{S}-\mathrm{O}-\mathrm{C}$ dihedral angles are 73.2 and $70.8^{\circ}$ ) resulted in the conformational ground state. At the highest level of theory used, the GT conformer $\left(\mathrm{O}-\mathrm{S}-\mathrm{O}-\mathrm{C}=+68.5\right.$ and $\left.-173.2^{\circ}\right)$ is $0.83 \mathrm{~kJ} \mathrm{~mol}^{-1}$ higher in energy than the $\mathrm{GG}$ form, while conformer $\mathrm{GG}^{\prime}\left(\mathrm{O}-\mathrm{S}-\mathrm{O}-\mathrm{C}=+85.7\right.$ and $\left.-85.7^{\circ}\right)$ has a relative energy of $1.18 \mathrm{~kJ} \mathrm{~mol}^{-1}$. The remaining two conformers ( $\mathrm{G}^{\prime} \mathrm{T}$ and $\mathrm{TT}$ ) are high-energy forms and not experimentally relevant. In consonance with the theoretical predictions, conformer GG was found to be the most stable conformer in the gaseous phase as well as in the low-temperature matrices. Annealing of the argon matrices first promotes the $\mathrm{GG}^{\prime} \rightarrow \mathrm{GT}$ isomerization, which is followed by conversion of GT into the most stable conformer. There is no evidence of occurrence of $\mathrm{GG}^{\prime} \rightarrow \mathrm{GG}$ direct conversion in the lowtemperature matrices. On the other hand, during deposition of the xenon matrices conformer $\mathrm{GG}^{\prime}$ totally converts to conformer GT. Two observations demonstrated this fact: no evidence of bands corresponding to $\mathrm{GG}^{\prime}$ were observed in xenon matrices and the GG/GT intensity ratio became similar to the GG/(GT + GG') intensity ratio observed in argon matrices. All these results could be explained by taking into account the relative values of the theoretically predicted energy barriers for the different isomerization processes: $\mathrm{GG}^{\prime} \rightarrow \mathrm{GT}$, $1.90 \mathrm{~kJ} \mathrm{~mol}^{-1}$; GT $\rightarrow \mathrm{GG}, 9.64 \mathrm{~kJ} \mathrm{~mol}^{-1}$; and $\mathrm{GG}^{\prime} \rightarrow \mathrm{GG}, 19.46 \mathrm{~kJ} \mathrm{~mol}^{-1}$.
\end{abstract}

\section{Introduction}

Organic sulfites have demonstrated practical applications as insecticides and plant growth regulators, among others uses. ${ }^{1}$ Dimethyl sulfite $\left(\mathrm{DMSO}_{3}\right)$ is the simplest member of the family and has been used as insect repellent and also experimentally identified as a mutagenic agent. It is a biologically meaningful odorant and is present, for instance, in male preputial glands. $\mathrm{DMSO}_{3}$ has also been described as attractive for conspecifics in rats. ${ }^{2}$

Despite their practical relevance, the available knowledge on the structural and spectroscopic properties of this type of compound is relatively scarce. This lack of information can be in part attributed to their relatively low stability. Indeed, organic sulfites have been generally found to be quite unstable compounds, occurring very often as elusive intermediate products of reaction. ${ }^{3,4}$

A few reports have appeared focusing on the reactivity of $\mathrm{DMSO}_{3}$ toward different nucleofiles in the gaseous phase, leading to the conclusion that its reactivity is strongly influenced by the nature of the nucleofilic substrate. ${ }^{5}$ The infrared and Raman spectra of liquid and solid phases of $\mathrm{DMSO}_{3}$ were investigated first by Klaeboe, in $1968,{ }^{6}$ who undertook the first tentative assignment of the fundamental vibrations of this compound. Although rotational isomerism had not been explic-

\footnotetext{
* Corresponding author. E-mail: rfausto@ci.uc.pt.

† Department of Chemistry, University of Coimbra.

$\doteqdot$ Universidad de Buenos Aires.

$\S$ Department of Chemical Engineering, University of Coimbra.
}

itly considered in the work of Klaeboe, such possibility (caused by restricted rotation around the $\mathrm{S}-\mathrm{O}$ bonds) was not excluded. This fact led Huong and Raducanu ${ }^{7}$ to perform a conformational study of $\mathrm{DMSO}_{3}$ and its perdeuterated isotopologue in the liquid state and in solutions of various solvents by infrared spectroscopy. In that work, the existence of a conformational equilibrium between two different types of conformers in diluted solutions was assumed: one type of conformers should have at least one $\mathrm{CH}_{3}$ group in the syn position relative to the $\mathrm{S}=\mathrm{O}$ group, while the other group of conformers should include all the remaining forms. As it will be shown in the present paper, this approach was not correct.

Additional vibrational spectroscopy studies on different sulfites (including several cyclic organic sulfites) in solutions of various solvents have also been reported, focusing essentially on the analysis of the $v(\mathrm{~S}=\mathrm{O})$ stretching band profile. ${ }^{8,9}$ In those studies, the possibility of using this spectral region to shed light on the conformational preferences of this type of compound was proposed, though no detailed conformational studies were presented.

Later on, the vibrational spectra of the liquid and crystalline states of $\mathrm{DMSO}_{3}$ were reinvestigated by Remizov et al. ${ }^{10}$ Two crystalline modifications of $\mathrm{DMSO}_{3}$ and perdeuterated $\mathrm{DMSO}_{3}$ were identified, with both crystals having the same probability of being obtained by warming of the glassy state produced by fast cooling of the sample to liquid nitrogen temperature. Very interestingly, both crystalline varieties were found to be stable within the temperature range $80-180 \mathrm{~K}$ (melting point), and no phase transitions between these two phases were observed. 

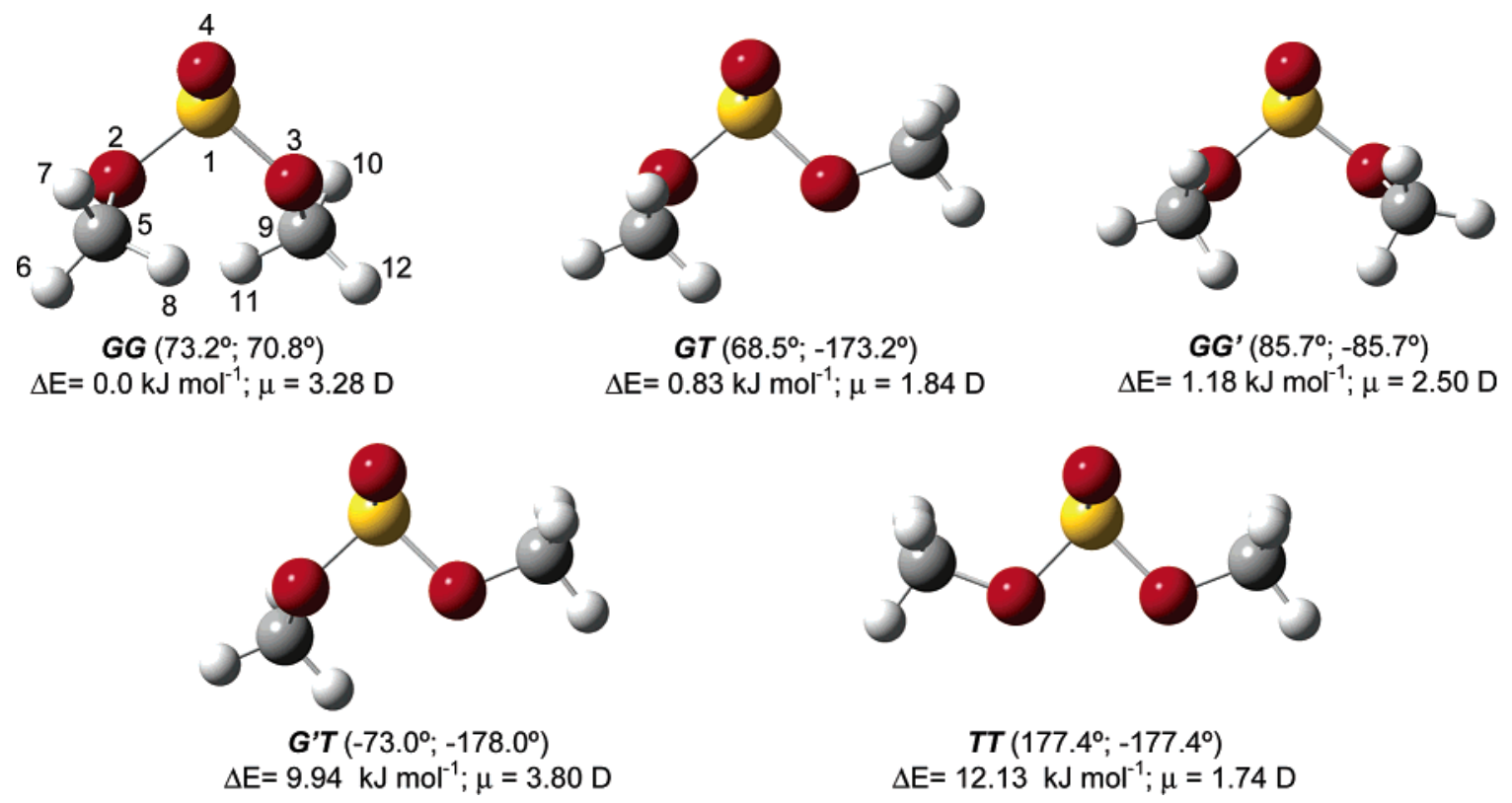

Figure 1. Conformers of $\mathrm{DMSO}_{3}$ with atom numbering scheme. Defining dihedral angles, relative energies, and dipole moments are also shown.

However, no attempt was made in that study to characterize conformationally the different phases observed.

The most recent study on the conformational preferences and vibrational spectra of $\mathrm{DMSO}_{3}$ was that of Odeurs et al., ${ }^{11}$ which was already published more than 10 years ago. On the basis of the analysis of the observed $v(\mathrm{~S}=\mathrm{O})$ band profile of the infrared spectrum of gaseous $\mathrm{DMSO}_{3}$, the conformational preferences of this molecule in the gaseous phase were investigated in that study. The conclusions pointed to the existence of two main conformers (GG and GT, in Figure 1), which should constitute the vast majority of the species present in the conformational equilibrium in the gas phase. While, as it will be shown later on in this paper, the study of Odeurs et al. ${ }^{11}$ undoubtedly constituted a considerable step forward in the direction of the understanding of the conformational preferences of $\mathrm{DMSO}_{3}$, its main conclusion was still far from the correct one.

Theoretically, the structure and vibrational spectra of $\mathrm{DMSO}_{3}$ had never been investigated hitherto. The main difficulty of employing theoretical methods for the computational study of compounds with sulfur-to-oxygen linkages has been the large computational resources that are required to undertake reliable predictions of their fundamental properties. For example, it is well-known that theoretical predictions of vibrational spectra of molecules with more usual linkages (e.g., $\mathrm{CH}, \mathrm{CO}, \mathrm{CN}, \mathrm{NO}$, $\mathrm{NH}$, and $\mathrm{OH}$, etc.) by ab initio or density functional theory (DFT) based methods usually lead to a general systematic overestimation of the vibrational frequencies, even when relatively modest basis sets are used in the calculations. This enables the uniform scaling procedure to be applied successfully in order to fit the calculated spectra to the experimental data and then obtain a good theoretical prediction of the spectra at relatively low computational cost. However, this is not the case for molecules with SO bonds, where, unless a quadruple- $\zeta$ basis set is used in the calculations, the theoretical calculations usually underestimate some of the frequencies relative to the experimentally observed ones, ${ }^{12,13}$ thus precluding the uniform scaling procedure to be applied successfully to these cases and imposing severe difficulties to the interpretation of the experimental data on the basis of the theoretical predictions.

In this work, the potential energy surface of $\mathrm{DMSO}_{3}$ was investigated at various levels of theory (DFT and MP2, with basis sets of different sizes, including the quadruple- $\zeta$, aug-ccpVQZ basis) in order to identify the relevant conformers of this molecule. The theoretically obtained structural, energetic, and vibrational data were then used to aid interpretation of the FTIR spectra of the compound isolated in solid argon or solid xenon, enabling, for the first time, the clear identification and full vibrational characterization of the three most stable conformers of the studied molecule, all of them being shown to exist in significant amounts in the gas phase, at room temperature.

\section{Materials and Methods}

Infrared Spectroscopy. Dimethyl sulfite was obtained from Aldrich (purity 99\%). The IR spectra were collected, with 0.5 $\mathrm{cm}^{-1}$ spectral resolution, on a Mattson (Infinity 60AR Series) Fourier transform infrared spectrometer, equipped with a deuterated triglycine sulfate (DTGS) detector and $\mathrm{Ge} / \mathrm{KBr}$ beam splitter. Necessary modifications of the sample compartment of the spectrometer were made in order to accommodate the cryostat head and allow efficient purging of the instrument by a stream of dry $\mathrm{N}_{2}$ to remove water and $\mathrm{CO}_{2}$ vapors.

In the matrix isolation experiments, a glass vacuum system and standard manometric procedures were used to deposit the matrix gas (argon N60 or xenon N48, both obtained from Air Liquide). Matrices were prepared by co-deposition, onto the cooled CsI substrate of the cryostat, of the matrix gas and $\mathrm{DMSO}_{3}$, which was sublimated using a specially designed doubly thermostatable Knudsen cell with shut-off possibility. ${ }^{14}$ The container of the Knudsen cell was kept at low temperature (ca. $173 \mathrm{~K}$ ) to reduce the vapor pressure of the compound over the solid and enable a better control of the amount of $\mathrm{DMSO}_{3}$ being deposited, to avoid the presence of aggregates in the deposited matrices. Identification of characteristic bands of aggregates was unequivocally made in a preliminary set of experiments by (1) comparing the spectra of matrices prepared with different concentrations and (2) annealing of dilute matrices up to temperatures at which they start to enable molecular diffusion to take place significantly. Temperatures of the nozzle varied from room temperature to $393 \mathrm{~K}$. All experiments were done on the basis of an APD Cryogenics close-cycle helium refrigeration system with a DE-202A expander. Different deposition temperatures were used, ranging from 9 to $30 \mathrm{~K}$ (Ar) 
TABLE 1: Calculated Relative Energies, Including Zero-Point Vibrational Contributions and Predicted Relative Populations, for the Various Conformers of Dimethyl Sulfite ${ }^{a}$

\begin{tabular}{|c|c|c|c|c|c|}
\hline \multirow[b]{3}{*}{ conformer } & \multicolumn{3}{|c|}{$\triangle \mathrm{EZPE}$} & & \\
\hline & \multirow{2}{*}{$\begin{array}{c}\text { B3LYP/ } \\
6-311++G(d, p)\end{array}$} & \multirow{2}{*}{$\begin{array}{c}\text { MP2/ } \\
6-31++G(d, p)\end{array}$} & \multirow{2}{*}{$\begin{array}{c}\text { B3LYP/ } \\
\text { aug-cc-pVQZ }\end{array}$} & \multicolumn{2}{|c|}{$\%$ population ${ }^{b}$} \\
\hline & & & & $298 \mathrm{~K}$ & $393 \mathrm{~K}$ \\
\hline GG & 1.10 & $\begin{array}{l}\mathbf{0 . 0} \\
(-1843534.53)^{c}\end{array}$ & $\begin{array}{l}\mathbf{0 . 0} \\
(-1847685.818)^{c}\end{array}$ & 48.8 & 45.8 \\
\hline GT & 0.84 & 0.87 & 0.83 & 35.0 & 35.5 \\
\hline $\mathrm{GG}^{\prime}$ & $\begin{array}{l}\text { 0.0 } \\
(-1847432.42)^{c}\end{array}$ & 1.38 & 1.18 & 15.1 & 15.9 \\
\hline $\mathrm{G}^{\prime} \mathrm{T}$ & 12.65 & 14.21 & 9.94 & 0.9 & 2.2 \\
\hline TT & 16.77 & 17.02 & 12.13 & 0.2 & 0.6 \\
\hline
\end{tabular}

${ }^{a}$ Energies in $\mathrm{kJ} \mathrm{mol}^{-1}$; conformers are depicted in Figure 1. ${ }^{b}$ Estimated using relative energies obtained at the B3LYP/aug-cc-pVQZ level of theory. ${ }^{c}$ Total energies with zero-point vibrational energy contribution.

or 9 to $50 \mathrm{~K}(\mathrm{Xe})$. After deposition of the compound, annealing experiments were performed until a temperature of $35 \mathrm{~K}(\mathrm{Ar})$ or $60 \mathrm{~K}(\mathrm{Xe})$ was attained.

Computational Methodology. The quantum chemical calculations were performed with Gaussian $98^{15}$ at the DFT and MP2 levels of theory, using the $6-311++\mathrm{G}(\mathrm{d}, \mathrm{p}), 6-31++\mathrm{G}-$ (d,p), and aug-cc-pVQZ basis sets. ${ }^{16-25}$ The DFT calculations were carried out with the three-parameter density functional abbreviated as B3LYP, which includes Becke's gradient exchange correction ${ }^{26}$ and the Lee, Yang, and Parr correlation functional. ${ }^{27}$

Conformations were optimized using the geometry direct inversion of the invariant subspace (GDIIS) method. ${ }^{28}$ Vibrational frequencies were calculated at each level of theory, and the nature of the stationary points on the potential energy surface resulting from optimization was determined by inspection of the corresponding calculated Hessian matrix. The optimized structures of all conformers described in this study were confirmed to correspond to true minimum energy conformations on the different potential energy surfaces investigated. Potential energy profiles for internal rotation were calculated by performing a relaxed scan on the MP2/6-31++G(d,p) PES along the relevant reaction coordinates, and the transition-state structures for conformational interconversion obtained using the synchronous transit-guided quasi-Newton (STQN) method. ${ }^{29}$

Effects of media on the MP2/6-31++G(d,p) PES were roughly evaluated by using polarizable continuum medium (PCM) self-consistent reaction field (SCRF) $)^{30-32}$ calculations for the compound in the noble gas. The results obtained using this approach were found to agree qualitatively with those obtained for the molecule in the vacuum in what is of concern to the critical parameters discussed in this paper.

Normal coordinate analyses were undertaken in the internal coordinates space as described by Schachtschneider, ${ }^{33}$ using the program BALGA and the optimized geometries and harmonic force constants resulting from the B3LYP/aug-cc-pVQZ calculations.

\section{Results and Discussion}

Geometries and Energies. In $\mathrm{DMSO}_{3}$, the $\mathrm{SO}_{3}$ moiety has a pyramidal geometry. The molecule has two internal rotation axes, defined around the $\mathrm{S}-\mathrm{O}$ bonds, which can give rise to conformational isomers.

To identify the minimum energy conformations of $\mathrm{DMSO}_{3}$, a systematic investigation on the potential energy surface of the molecule was undertaken using the B3LYP/6-311++G(d,p) method. Five different conformers were found (Figure 1), with the GG, GT, and $\mathrm{G}^{\prime} \mathrm{T}$ forms, belonging to the $C_{1}$ point group, being doubly degenerated by symmetry, and $\mathrm{GG}^{\prime}$ and $\mathrm{TT}$ corresponding to unique species, with $C_{\mathrm{s}}$ symmetry. The nomenclature for the conformers here adopted follows closely that previously used for dimethyl sulfate. ${ }^{13}$

Table 1 displays the predicted relative energies (including zero-point energy corrections) of the conformers, obtained at the different levels of theory used in this study. All calculations predict the GG, GT, and $\mathrm{GG}^{\prime}$ forms to have similar energies (to within $1.5 \mathrm{~kJ} \mathrm{~mol}^{-1}$ ) and conformers $\mathrm{G}^{\prime} \mathrm{T}$ and $\mathrm{TT}$ as corresponding to high-energy structures $\left(\Delta E>\mathrm{ca} .10 \mathrm{~kJ} \mathrm{~mol}^{-1}\right)$. However, the predicted order of stability of the three low-energy conformers was found to be dependent on the level of theory used: the B3LYP/6-311++G(d,p) calculations predicted $\mathrm{GG}^{\prime}$ as the most stable form, followed by GT and GG (see Table 1), whereas both the MP2/6-31++G(d,p) and B3LYP/aug-ccpVQZ calculations yield GG as the most stable form, followed by GT $\left(\triangle E\left(\mathrm{~B} 3 \mathrm{LYP} / \mathrm{aug}\right.\right.$-cc-pVQZ) $\left.=0.83 \mathrm{~kJ} \mathrm{~mol}^{-1}\right)$ and $\mathrm{GG}^{\prime}$ $\left(\triangle E\left(\mathrm{~B} 3 \mathrm{LYP} /\right.\right.$ aug-cc-pVQZ) $\left.=1.18 \mathrm{~kJ} \mathrm{~mol}^{-1}\right)$.

According to the optimization performed at the B3LYP/augcc-pVQZ level of theory, the characteristic $\mathrm{C}_{5}-\mathrm{O}_{2}-\mathrm{S}_{1}-\mathrm{O}_{3}$ and $\mathrm{C}_{9}-\mathrm{O}_{3}-\mathrm{S}_{1}-\mathrm{O}_{2}$ dihedral angles (deg) for the different conformers are as follows: $(+73.2,+70.8) ;(+68.5,-173.2) ;(+85.7$, $-85.7)$; (-73.0, -178.0); and (+177.4, -177.4), for GG, GT, $\mathrm{GG}^{\prime}, \mathrm{G}$ 'T, and TT, respectively. It is worth mentioning that the $\mathrm{G}^{\prime} \mathrm{G}$ conformation, where the two methyl groups are oriented toward the apex of the pyramid defined by the $\mathrm{SO}_{3}$ fragment, was found not to be a minimum in the potential energy surface of $\mathrm{DMSO}_{3}$ at all levels of theory used (in all cases, minimization of the $\mathrm{G}^{\prime} \mathrm{G}$ structure was found to converge to the $\mathrm{G}^{\prime} \mathrm{T}$ conformer). The optimized geometries for the five conformers of $\mathrm{DMSO}_{3}$ are provided as electronic Supporting Information (ESI), Table S01.

The relative stability of the conformers can be explained by taking into account a balance between the repulsive interactions between the nonbonding pairs of electrons of the methoxyl oxygen atoms or between the methyl groups, in one side, and the attractive interactions between methyl hydrogen and oxygen atoms.

In the most stable form predicted by the highest level calculations (conformer GG), there are no repulsive interactions between nonbonding pairs of electrons and both methyl groups are as separated as possible from each other (distance $\mathrm{C}_{5} \cdots \mathrm{C}_{9}$ $=387.1 \mathrm{pm}$ ), whereas $\mathrm{H} \cdots \mathrm{O}$ attractive interactions exist between the following pairs of atoms: $\mathrm{H}_{7} \cdots \mathrm{O}_{4}, \mathrm{H}_{11} \cdots \mathrm{O}_{2}$, and $\mathrm{H}_{8} \cdots \mathrm{O}_{3}$ (see Figure 1). The $\mathrm{H}_{7} \cdots \mathrm{O}_{4}$ attraction is of particular importance in energetic terms, since it involves participation of the more negative $\mathrm{S}=\mathrm{O}$ oxygen atom (the calculated B3LYP/ aug-cc-pVQZ Mulliken charge on $\mathrm{O}_{4}$ is ca. $-1.04 e$, while those on $\mathrm{O}_{2}$ and $\mathrm{O}_{3}$ are ca. $-0.75 e$ ).

In the second most stable conformer (GT), one $\mathrm{O}_{2} \cdots \mathrm{O}_{3}$ loneelectron pairs repulsive interaction exists, such as in the third and fourth most stable forms ( $\mathrm{GG}^{\prime}$ and $\mathrm{G}^{\prime} \mathrm{T}$, respectively). 

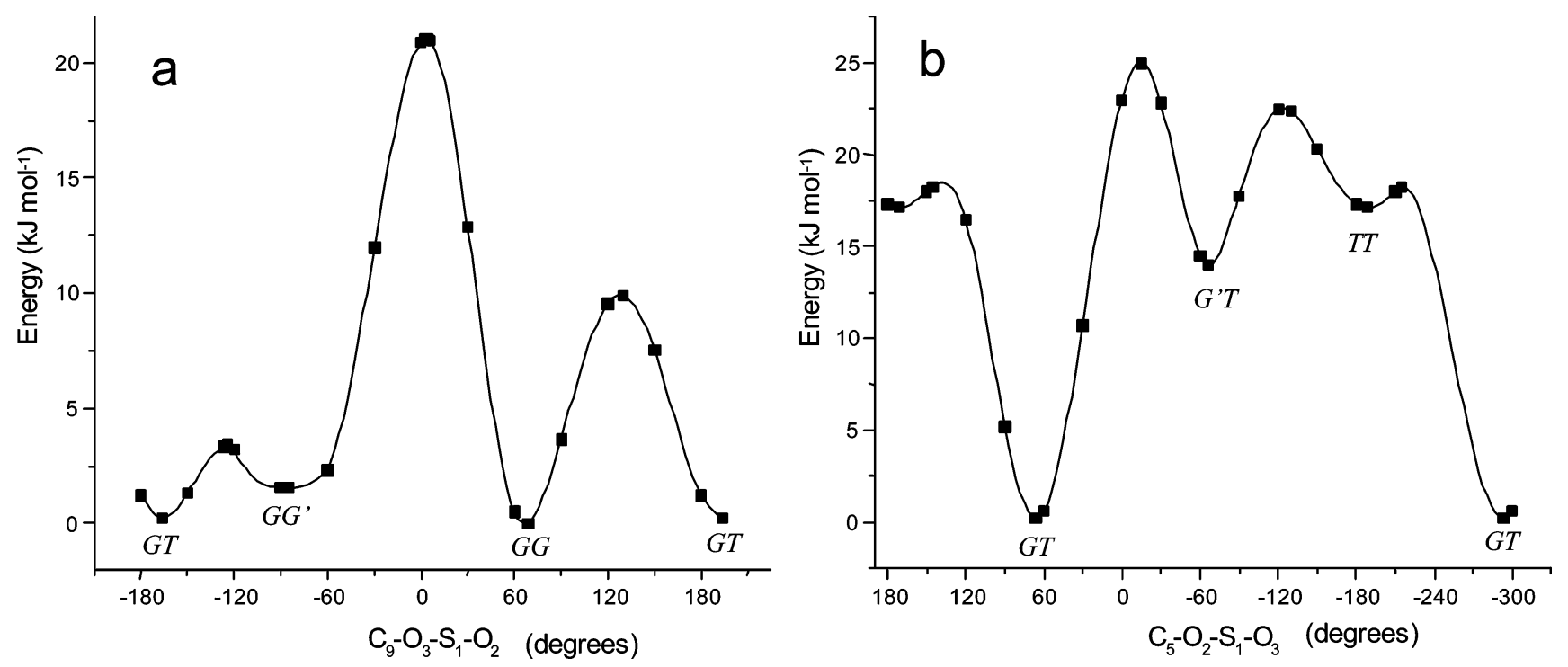

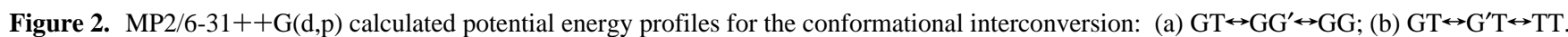

However, in conformer GT, there are also three $\mathrm{H} \cdots \mathrm{O}$ attractive interactions, two of which involve $\mathrm{O}_{4}\left(\mathrm{H}_{7} \cdots \mathrm{O}_{4}, \mathrm{H}_{10} \cdots \mathrm{O}_{4}\right.$, and $\mathrm{H}_{8} \cdots \mathrm{O}_{3}$; see Figure 1), that compensate for the $\mathrm{O}_{2} \cdots \mathrm{O}_{3}$ repulsive interaction. In $\mathrm{GG}^{\prime}$, besides the $\mathrm{O}_{2} \cdots \mathrm{O}_{3}$ repulsive interaction, there is also a repulsive interaction between the two methyl groups, but, on the other hand, in this conformer the number of stabilizing $\mathrm{H} \cdots \mathrm{O}$ interactions is maximized (two strong $\mathrm{H} \cdots \mathrm{O}$ interactions involving $\mathrm{H}_{7}, \mathrm{H}_{9}$, and $\mathrm{O}_{4}$ and two weaker interactions, $\mathrm{H}_{8} \cdots \mathrm{O}_{3}$ and $\mathrm{H}_{10} \cdots \mathrm{O}_{2}$; see Figure 1), justifying its relatively low energy. On the other hand, in the higher energy G'T conformer, only the $\mathrm{H}_{10} \cdots \mathrm{O}_{4}$ and $\mathrm{H}_{7} \cdots \mathrm{O}_{3}$ stabilizing interactions oppose the $\mathrm{O}_{2} \cdots \mathrm{O}_{3}$ repulsive interaction, making this conformer considerably less stable than the previous three.

Finally, the TT conformer is the highest energy form due to the presence of two $\mathrm{O}_{2} \cdots \mathrm{O}_{3}$ lone-electron pairs' repulsive interactions, which are only compensated for by two $\mathrm{H} \cdots \mathrm{O}$ interactions (between $\mathrm{H}_{8}$ and $\mathrm{H}_{10}$, and $\mathrm{O}_{4}$; see Figure 1).

Comparing now the relative conformational energies calculated by the three methods used, it can be concluded that both the MP2 and B3LYP/aug-cc-pVQZ calculations seem to give a greater importance to the $\mathrm{H} \cdots \mathrm{O}$ attractive interactions relative to the $\mathrm{O}_{2} \cdots \mathrm{O}_{3}$ repulsions than the lowest level B3LYP/6$311++\mathrm{G}(\mathrm{d}, \mathrm{p})$ calculations. As a consequence, conformer $\mathrm{GG}$, where only the first type of interaction is present, gains an additional stabilization and appears as the most stable conformer. Note that the better description of $\mathrm{H} \cdots \mathrm{O}$ attractive interactions by higher level theoretical calculations has been found to be a general rule, resulting mainly from the greater flexibility of the wave function associated with a better theoretical model.

The potential energy profiles for interconversion between the different conformers of $\mathrm{DMSO}_{3}$ are shown in Figure 2. The curves presented in this figure were obtained at the MP2/6$31++\mathrm{G}(\mathrm{d}, \mathrm{p})$ level of calculation, since their computation at the B3LYP/aug-cc-pVQZ level is beyond the affordable amount of computer time.

Figure $2 \mathrm{a}$ presents the potential energy profile along the $\mathrm{GT} \leftrightarrow \mathrm{GG}^{\prime} \mathrm{GG} \leftrightarrow \mathrm{GT}$ path, corresponding to the internal rotation around the $\mathrm{O}_{3}-\mathrm{S}_{1}$ bond with the $\mathrm{C}_{5}-\mathrm{O}_{2}-\mathrm{S}_{1}-\mathrm{O}_{3}$ dihedral angle assuming the gauche $(\mathrm{G})$ geometry. Since the relative energies of these three conformers are similar, all three forms shall be present at the equilibrium in the gaseous phase in significant amounts (see Table 1). The relative energy barriers separating these conformers can then be expected to be of fundamental importance for the analysis of the experimental results obtained in the present study, which, as described in detail below, include low-temperature thermally induced conformational isomerization of $\mathrm{DMSO}_{3}$ isolated in solid inert-gas matrices. In this context, the energy barriers for conversion of higher energy forms into lower energy forms assume special importance, once this is the type of processes expected to occur upon annealing of the matrices to higher temperatures ${ }^{34}$ or resulting from conformational cooling ${ }^{35,36}$ during deposition of the matrices.

Along the $\mathrm{GT} \leftrightarrow \mathrm{GG}^{\prime} \leftrightarrow \mathrm{GG} \leftrightarrow \mathrm{GT}$ path, the calculated barrier for conversion of $\mathrm{GG}^{\prime}$ into $\mathrm{GT}$ is $1.90 \mathrm{~kJ} \mathrm{~mol}^{-1}$, whereas that associated with the $\mathrm{GT} \rightarrow \mathrm{GG}$ conversion is $9.64 \mathrm{~kJ} \mathrm{~mol}^{-1}$ (see Figure 2a). According to the Barnes relationship, ${ }^{34}$ it can be concluded that both barriers are high enough to allow for the trapping of all three conformers (GG, GT, and GG') in the lowtemperature $(9-15 \mathrm{~K})$ argon matrices, and small enough to be overcome by annealing of the matrices, thus enabling conformational isomerization to take place. On the other hand, xenon is a considerably more efficient matrix gas for observation of conformational cooling during deposition of the matrix, ${ }^{36}$ and the low-energy barrier process leading to conversion of the $\mathrm{GG}^{\prime}$ conformer into the GT form during deposition might be expected to occur. As it will be described in detail later in this paper, the experimental results fully confirmed these theoretical predictions.

The barrier associated with the $\mathrm{GG}^{\prime} \rightarrow \mathrm{GG}$ conversion is much higher $\left(19.46 \mathrm{~kJ} \mathrm{~mol}^{-1}\right)$ than those associated with the $\mathrm{GG}^{\prime} \rightarrow \mathrm{GT}$ and $\mathrm{GT} \rightarrow \mathrm{GG}$ conversions, because during this process both methyl groups are forced to pass through the considerably strained face-to-face position. For an energy barrier of this magnitude, the Barnes relationship indicates that a matrix temperature of ca. $70 \mathrm{~K}$ must be reached to allow for the $\mathrm{GG}^{\prime} \rightarrow \mathrm{GG}$ conversion to start being observed. This temperature is, however, inaccessible to an argon matrix. On the other hand, while being in principle attainable in the case of the xenon matrices, at this relatively high temperature aggregation could be expected to be extensive, thus precluding the experimental observation of the direct $\mathrm{GG}^{\prime} \rightarrow \mathrm{GG}$ isomerization also when this matrix gas is used.

The rotation around the $\mathrm{O}_{2}-\mathrm{S}_{1}$ bond with the $\mathrm{C}_{9}-\mathrm{O}_{3}-\mathrm{S}_{1}-$ $\mathrm{O}_{2}$ dihedral angle assuming the trans (T) geometry defines the $\mathrm{GT} \leftrightarrow \mathrm{G}^{\prime} \mathrm{T} \leftrightarrow \mathrm{TT} \leftrightarrow \mathrm{GT}$ path (Figure $2 \mathrm{~b}$ ), involving the high-energy G'T and TT conformers and the second most stable form (GT). 


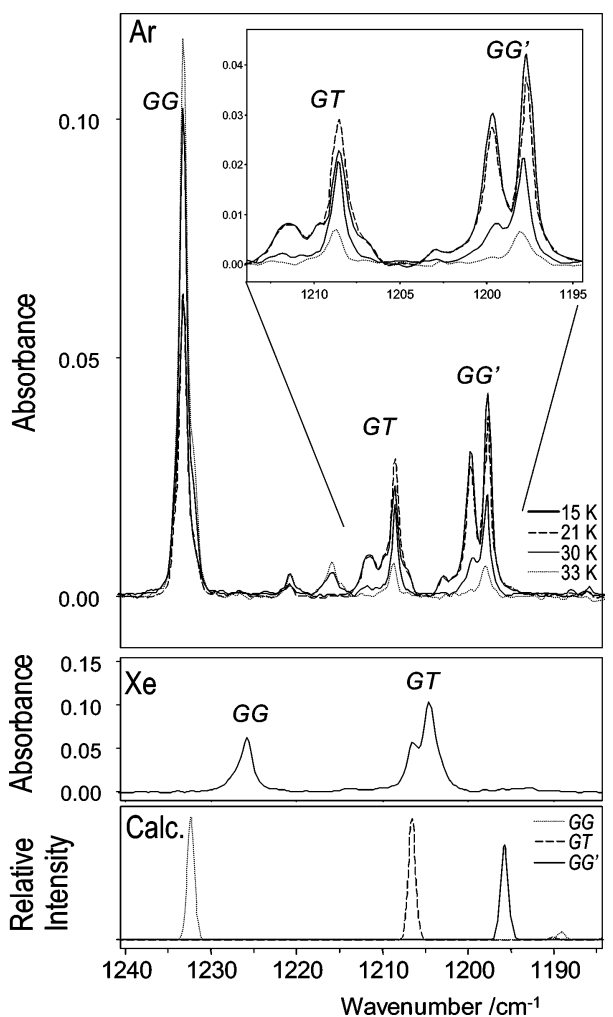

Figure 3. Infrared spectra of $\mathrm{DMSO}_{3}$ in an argon matrix (obtained immediately after deposition at $15 \mathrm{~K}$ and after annealing at 21,30 and $33 \mathrm{~K})$, in a xenon matrix $(T=9 \mathrm{~K})$, and calculated spectra for the $\mathrm{GG}$, $\mathrm{GT}$, and $\mathrm{GG}^{\prime}$ conformers for the $1185-1240 \mathrm{~cm}^{-1}$ region.

Accordingly to the calculations, the total population of the $\mathrm{G}^{\prime} \mathrm{T}$ and TT forms in the gas-phase equilibrium, within the temperature range covered in this study (room temperature to $393 \mathrm{~K}$ ), is less than $3 \%$. Hence, these two forms are not expected to be observable in the matrices.

In summary, in the as-deposited argon matrices it is expectable to observe three conformers: GG, GT, and GG'. The GT conformer is predicted to be convertible directly into the most stable GG form upon annealing of the matrices, while the $\mathrm{G}^{\prime} \mathrm{G}$ form is only expected to be convertible into the GG form in a two-step reaction: $\mathrm{GG}^{\prime} \rightarrow \mathrm{GT} \rightarrow \mathrm{GG}$. In the xenon matrices, the theoretical calculations indicated that form $\mathrm{GG}^{\prime}$ might not be observed, due to conversion to the GT form during the matrix deposition. Both conformers $\mathrm{G}^{\prime} \mathrm{T}$ and $\mathrm{TT}$ are predicted not to be observable experimentally.

Vibrational Spectra. $\mathrm{DMSO}_{3}$ has 30 fundamental vibrations. For all five conformers (GG, GT, GG', G'T, and TT) all fundamental vibrations are predicted to be symmetry-allowed in the infrared. Tables S02 and S03 (ESI) display the definition of the internal coordinates used in the normal-coordinate analysis undertaken in this study. The B3LYP/aug-cc-pVQZ calculated spectra for all the conformers of $\mathrm{DMSO}_{3}$ (including the nonexperimentally observed $\mathrm{G}^{\prime} \mathrm{T}$ and $\mathrm{TT}$ forms) and potential energy distributions (PED) are given in Tables S04-S08 (ESI).

Figures 3-5 depicts the as-deposited spectra of $\mathrm{DMSO}_{3}$ in an $\operatorname{argon}$ matrix $(T=15 \mathrm{~K})$, with the valve nozzle at room temperature $(298 \mathrm{~K})$, and those resulting from annealing of the sample up to $33 \mathrm{~K}$. At room temperature, the populations of the three low-energy conformers of $\mathrm{DMSO}_{3}$ predicted by the B3LYP/aug-cc-pVQZ calculations are $49 \%$ for GG, 35\% for GT, and $15 \%$ for $\mathrm{GG}^{\prime}$; i.e., all these forms should contribute significantly to the observed spectra, assuming that the gasphase equilibrium can be efficiently trapped in the matrix.

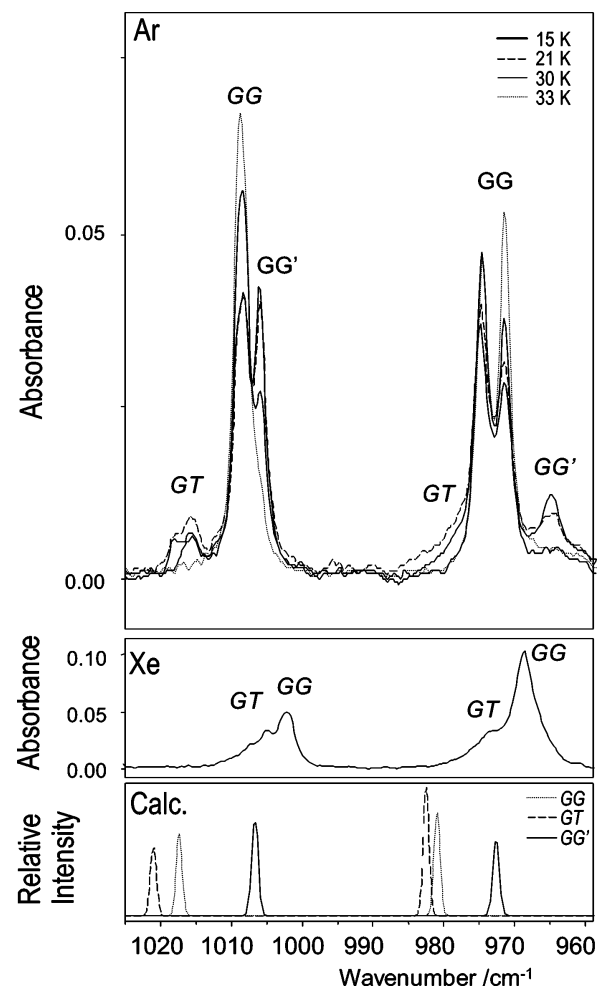

Figure 4. Same conditions as in Figure 3 for the $960-1020 \mathrm{~cm}^{-1}$ region.
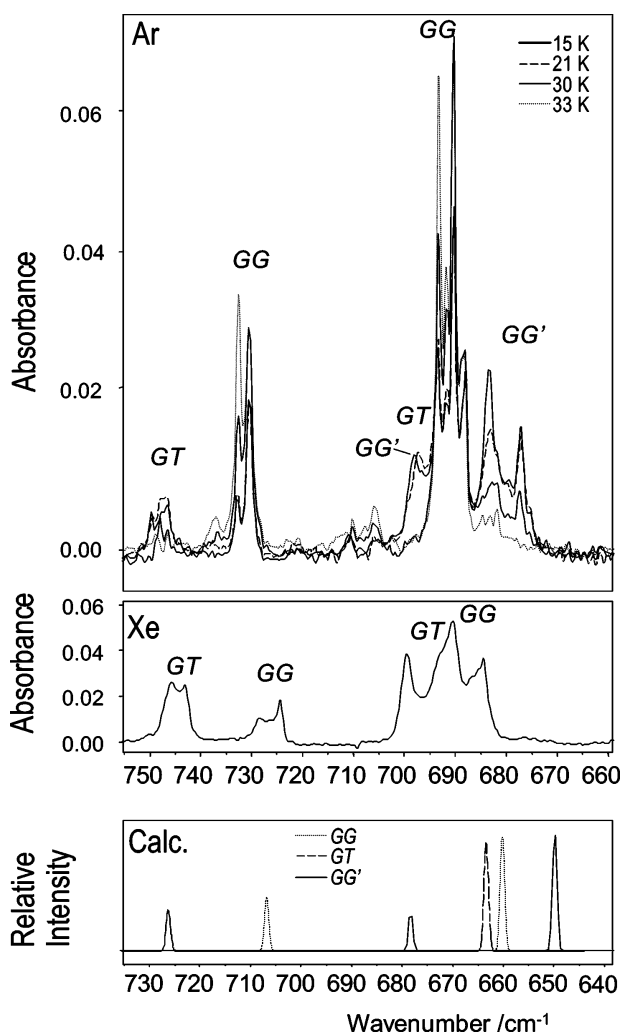

Figure 5. Same conditions as in Figure 3 for the $660-755 \mathrm{~cm}^{-1}$ region.

Indeed, the spectrum of the as-deposited argon matrix reveals the presence of the three conformers, as it can easily be observed by comparing this spectrum with the B3LYP/aug-cc-pVQZ calculated spectra for these conformers GG, GT, and $\mathrm{GG}^{\prime}$ (see Figures 3-5). In the $v(\mathrm{~S}=\mathrm{O})$ stretching region $(1190-1240$ $\mathrm{cm}^{-1}$ spectral range), the three conformers are predicted to give rise to well-separated bands at 1231.7 (GG), 1206.0 (GT), and 
TABLE 2: Observed Frequencies $\left(\mathrm{cm}^{-1}\right)$ for the GG Form of Dimethyl Sulfite Monomer in Argon and Xenon Matrices (B3LYP/aug-cc-pVQZ calculated frequencies and intensities $\left(\mathrm{km} \mathrm{mol}^{-1}\right)$ are given for comparison $)^{a}$

\begin{tabular}{|c|c|c|c|c|c|c|c|c|}
\hline \multirow[b]{2}{*}{$\begin{array}{c}\text { approx } \\
\text { description }\end{array}$} & \multirow[b]{2}{*}{$\begin{array}{c}\text { calcd } \\
\text { frequency }\end{array}$} & \multirow[b]{2}{*}{$\begin{array}{c}\text { calcd } \\
\text { intensity }\end{array}$} & \multicolumn{3}{|c|}{$\begin{array}{l}\text { obsd freq } \\
\operatorname{Ar}(9 \mathrm{~K})\end{array}$} & \multicolumn{3}{|c|}{$\begin{array}{l}\text { obsd freq } \\
\text { Xe }(9 \mathrm{~K})\end{array}$} \\
\hline & & & $\begin{array}{c}\text { more } \\
\text { stable site }\end{array}$ & & $\begin{array}{c}\text { less } \\
\text { stable site }\end{array}$ & $\begin{array}{c}\text { more } \\
\text { stable site }\end{array}$ & & $\begin{array}{c}\text { less } \\
\text { stable site }\end{array}$ \\
\hline$v\left(\mathrm{C} 9-\mathrm{H}_{3}\right)^{\prime}$ as & 3147.2 & 6.1 & & 3028.0 & & & 3022.3 & \\
\hline$v\left(\mathrm{C} 5-\mathrm{H}_{3}\right)^{\prime}$ as & 3133.7 & 9.4 & & 3028.0 & & & 3022.3 & \\
\hline$v\left(\mathrm{C} 9-\mathrm{H}_{3}\right)^{\prime \prime}$ as & 3124.6 & 14.6 & & 3014.5 & & & 3009.6 & \\
\hline$v\left(\mathrm{C} 5-\mathrm{H}_{3}\right)^{\prime \prime}$ as & 3089.4 & 22.8 & & 3005.1 & & & 3003.9 & \\
\hline$v\left(\mathrm{C} 9-\mathrm{H}_{3}\right)_{\mathrm{s}}$ & 3048.0 & 30.4 & & 2960.5 & & & $2969.5 / 2945.4$ & \\
\hline$v\left(\mathrm{C} 5-\mathrm{H}_{3}\right)_{\mathrm{s}}$ & 3024.2 & 41.6 & & 2955.1 & & & $2935.2 / 2928.8$ & \\
\hline$\delta\left(\mathrm{C} 9-\mathrm{H}_{3}\right)^{\prime}{ }_{\text {as }}$ & 1509.5 & 4.8 & & 1469.1 & & & 1462.4 & \\
\hline$\delta\left(\mathrm{C} 5-\mathrm{H}_{3}\right)^{\prime \prime}$ as & 1504.8 & 13.4 & & 1464.5 & & & 1458.5 & \\
\hline$\delta\left(\mathrm{C} 5-\mathrm{H}_{3}\right)^{\prime}$ as & 1492.0 & 9.3 & & 1455.7 & & & 1449.9 & \\
\hline$\delta\left(\mathrm{C} 9-\mathrm{H}_{3}\right)^{\prime \prime}$ as & 1485.7 & 7.9 & & 1451.3 & & & 1445.7 & \\
\hline$\delta\left(\mathrm{C} 5-\mathrm{H}_{3}\right)_{\mathrm{s}}$ & 1467.9 & 0.3 & & 1446.8 & & & 1442.9 & \\
\hline$\delta\left(\mathrm{C} 9-\mathrm{H}_{3}\right)_{\mathrm{s}}$ & 1458.7 & 0.3 & & 1428.9 & & & n.o. ${ }^{b}$ & \\
\hline$v(\mathrm{~S}=\mathrm{O})$ & 1231.7 & 151.6 & 1233.2 & & 1231.8 & 1225.9 & & 1227.5 \\
\hline$\gamma\left(\mathrm{C} 5-\mathrm{H}_{3}\right)^{\prime}$ & 1188.5 & 9.3 & & 1185.4 & & & 1192.6 & \\
\hline$\gamma\left(\mathrm{C} 9-\mathrm{H}_{3}\right)^{\prime}$ & 1178.8 & 0.7 & & n.o. ${ }^{b}$ & & & n.o. ${ }^{b}$ & \\
\hline$\gamma\left(\mathrm{C} 5-\mathrm{H}_{3}\right)^{\prime \prime}$ & 1174.6 & 0.7 & & n.o. ${ }^{b}$ & & & n.o. ${ }^{b}$ & \\
\hline$\gamma\left(\mathrm{C} 9-\mathrm{H}_{3}\right)^{\prime \prime}$ & 1169.8 & 2.2 & & 1165.7 & & & 1169.5 & \\
\hline$v(\mathrm{C} 5-\mathrm{O})$ & 1017.5 & 59.1 & 1009.7 & & 1009.2 & & 1002.5 & \\
\hline$v(\mathrm{C} 9-\mathrm{O})$ & 981.1 & 99.2 & 972.1 & & 975.6 & & 969.2 & \\
\hline$\gamma(\mathrm{S}=\mathrm{O})$ & 707.7 & 10.5 & 733.2 & & 730.8 & 724.7 & & $728.8 / 727.1$ \\
\hline$v(\mathrm{~S}-\mathrm{O} 2)$ & 661.1 & 36.6 & $693.8 / 688.5$ & & 692.1/690.7/689.1 & 684.8 & & 690.8 \\
\hline$v(\mathrm{~S}-\mathrm{O} 3)$ & 563.3 & 7.0 & & 578.2 & & & 580.0 & \\
\hline$\delta(\mathrm{OSO})$ & 427.0 & 1.1 & & n.o. ${ }^{b}$ & & & n.o. ${ }^{b}$ & \\
\hline$\delta(\mathrm{S}=\mathrm{O})$ & 401.5 & 7.4 & & n.o. ${ }^{b}$ & & & n.o. ${ }^{b}$ & \\
\hline$\delta(\mathrm{S}-\mathrm{O} 3-\mathrm{C} 9)$ & 250.3 & 12.0 & & n.o. ${ }^{b}$ & & & n.o. ${ }^{b}$ & \\
\hline$\delta\left(\mathrm{S}-\mathrm{O}_{2}-\mathrm{C} 5\right)$ & 241.8 & 1.1 & & n.o. ${ }^{b}$ & & & n.o. ${ }^{b}$ & \\
\hline$\tau(\mathrm{S}-\mathrm{O} 3)$ & 138.3 & 4.1 & & n.i..$^{c}$ & & & n.i..$^{c}$ & \\
\hline$\tau\left(\mathrm{C} 5-\mathrm{H}_{3}\right)$ & 91.3 & 1.0 & & n.i. ${ }^{c}$ & & & n.i..$^{c}$ & \\
\hline$\tau\left(\mathrm{C} 9-\mathrm{H}_{3}\right)$ & 84.6 & 0.3 & & n.i. ${ }^{c}$ & & & n.i..$^{c}$ & \\
\hline$\tau(\mathrm{S}-\mathrm{O} 2)$ & 77.3 & 2.4 & & n.i..$^{c}$ & & & n.i. ${ }^{c}$ & \\
\hline
\end{tabular}

${ }^{a} \nu$, bond stretching, $\delta$, bending, $\gamma$, rocking, $\tau$, torsion, s, symmetric, as, antisymmetric. See Table S02 of the Supporting Information for definitions of internal coordinates. ${ }^{b}$ Not observed. ${ }^{c}$ Not investigated.

$1195.7 \mathrm{~cm}^{-1}\left(\mathrm{GG}^{\prime}\right)$, corresponding to the features observed nearly at the same frequencies (see Figure 3). For all conformers, the experimental spectrum exhibits band-splitting (that is more evident for the features assigned to the $\mathrm{GT}$ and $\mathrm{GG}^{\prime}$ forms) due to occupancy of different matrix sites. Upon annealing of the matrix up to $21 \mathrm{~K}$, the bands ascribed to conformer $\mathrm{GG}^{\prime}$ decrease in intensity, whereas those originated in conformer GT became more intense. On the other hand, the bands due to conformer GG do not change their intensity. These results indicate that within the temperature range of $15-21 \mathrm{~K}$ conversion of $\mathrm{GG}^{\prime}$ conformer into the GT form takes place. Such observation is in consonance with the theoretically predicted low-energy barrier for the $\mathrm{GG}^{\prime} \rightarrow \mathrm{GT}$ isomerization (1.90 $\mathrm{kJ} \mathrm{mol}^{-1}$; see Figure 2) and demonstrates that, as for the gaseous phase, GT is also more stable than $\mathrm{GG}^{\prime}$ in an argon matrix. It shall, however, be pointed out that the intensity changes showed by the bands originated in different matrix sites exhibit different behavior upon annealing, revealing that the stability of both conformers in the different matrix sites shall differ substantially. In Tables 2, 3, and 4 , the band assignments take into consideration the different stabilities of the sites for all three conformers. In the case of GT and $\mathrm{GG}^{\prime}$, the most stable matrix sites are associated with the $v\left(\mathrm{~S}=\mathrm{O}\right.$ ) stretching bands observed at $1208.6 \mathrm{~cm}^{-1}$ (with a shoulder at $1207.0 \mathrm{~cm}^{-1}$ ) and $1197.7 \mathrm{~cm}^{-1}$, respectively (see Figure 3).

Continuing to increase the temperature of the matrix up to $33 \mathrm{~K}$, both $\mathrm{GT}$ and $\mathrm{GG}^{\prime}$ associated bands decrease in intensity, while those due to GG become more intense. Simultaneously, bands due to aggregates start to be observed (e.g., bands at 1220.8 and $1215.8 \mathrm{~cm}^{-1}$; see Figure 3). Hence, the experimental data fully confirm the theoretical predictions made in the previous section (which assume that no appreciable changes in the gas-phase potential energy surface of $\mathrm{DMSO}_{3}$ were introduced by isolation of the compound in an argon matrix), clearly revealing that (i) conformer GG corresponds to the most stable conformer for $\mathrm{DMSO}_{3}$ and (ii) the $\mathrm{GT} \rightarrow \mathrm{GG}$ isomerization can only take place at a higher temperature than the $\mathrm{GG}^{\prime} \rightarrow \mathrm{GT}$ isomerization, due to the higher energy barrier associated with the first process (9.64 vs $1.90 \mathrm{~kJ} \mathrm{~mol}^{-1}$; see Figure $2 \mathrm{a}$ ). It is interesting to note that, at $33 \mathrm{~K}$, only the most stable sites of both GT and $\mathrm{GG}^{\prime}$ subsist (in minor amounts), whereas the less stable sites of these two conformers become completely depopulated due to the above-mentioned isomerization processes (at $33 \mathrm{~K}$ aggregation can still be considered negligible). Hence, in its most stable matrix site, $\mathrm{GG}^{\prime}$ appears to be more stable than GT in at least some of their less stable sites. Such possibility is not surprising, taking into consideration the very small energy difference between GG $^{\prime}$ and GT predicted by the calculations $\left(0.35 \mathrm{~kJ} \mathrm{~mol}^{-1}\right)$. Furthermore, it seems also to be supported by the fact that during the first stages of the annealing $(15-21 \mathrm{~K})$ only the bands ascribed to the most stable GT site increase in intensity (see Figure 3). However, intersite conversions of either GT or $\mathrm{GG}^{\prime}$ (particularly in this latter case, that can be easily inferred to take place simultaneously with $\mathrm{GG}^{\prime} \rightarrow \mathrm{GT}$ isomerization by noticing that bands assigned to more than one $\mathrm{GG}^{\prime}$ site decrease in intensity during the first stages of the annealing; see Figure 3) strongly complicate this picture, and some caution regarding this conclusion is advised. The alternative putative explanation for the subsistence of a minor amount of $\mathrm{GG}^{\prime}$ in its most stable site in later stages of annealing, which assumes that 
TABLE 3: Observed Frequencies $\left(\mathrm{cm}^{-1}\right)$ for the GT Form of Dimethyl Sulfite Monomer in Argon and Xenon Matrices (B3LYP/aug-cc-pVQZ calculated frequencies and intensities $\left(\mathrm{km} \mathrm{mol}^{-1}\right)$ are given for comparison $)^{a}$

\begin{tabular}{|c|c|c|c|c|c|c|c|c|}
\hline \multirow[b]{2}{*}{$\begin{array}{c}\text { approx } \\
\text { description }\end{array}$} & \multirow[b]{2}{*}{$\begin{array}{c}\text { calcd } \\
\text { frequency }\end{array}$} & \multirow[b]{2}{*}{$\begin{array}{c}\text { calcd } \\
\text { intensity }\end{array}$} & \multicolumn{3}{|c|}{$\begin{array}{l}\text { obsd freq } \\
\operatorname{Ar}(9 \mathrm{~K})\end{array}$} & \multicolumn{3}{|c|}{$\begin{array}{l}\text { obsd freq } \\
\text { Xe }(9 \mathrm{~K})\end{array}$} \\
\hline & & & $\begin{array}{c}\text { more } \\
\text { stable site }\end{array}$ & & $\begin{array}{c}\text { less } \\
\text { stable site }\end{array}$ & $\begin{array}{c}\text { more } \\
\text { stable site }\end{array}$ & & $\begin{array}{c}\text { less } \\
\text { stable site }\end{array}$ \\
\hline$v\left(\mathrm{C} 5-\mathrm{H}_{3}\right)^{\prime}$ as & 3150.4 & 7.3 & & 3028.0 & & & 3022.3 & \\
\hline$v\left(\mathrm{C} 5-\mathrm{H}_{3}\right)^{\prime \prime}$ as & 3135.1 & 8.8 & & 3028.0 & & & 3022.3 & \\
\hline$v\left(\mathrm{C} 9-\mathrm{H}_{3}\right)^{\prime}$ as & 3134.1 & 10.0 & & 3028.0 & & & 3022.3 & \\
\hline$v\left(\mathrm{C} 9-\mathrm{H}_{3}\right)^{\prime \prime}$ as & 3095.4 & 19.4 & & 3005.1 & & & 3003.9 & \\
\hline$v\left(\mathrm{C} 5-\mathrm{H}_{3}\right) \mathrm{s}$ & 3055.2 & 30.2 & & 2960.5 & & & $2969.5 / 2945.4$ & \\
\hline$v\left(\mathrm{C} 9-\mathrm{H}_{3}\right) \mathrm{s}$ & 3020.8 & 49.3 & & 2952.8 & & & $2935.2 / 2928.8$ & \\
\hline$\delta\left(\mathrm{C} 9-\mathrm{H}_{3}\right)^{\prime}$ as & 1508.1 & 14.4 & & 1469.1 & & & 1462.4 & \\
\hline$\delta\left(\mathrm{C} 5-\mathrm{H}_{3}\right)^{\prime \prime}$ as & 1507.3 & 6.8 & & 1467.8 & & & 1458.5 & \\
\hline$\delta\left(\mathrm{C} 9-\mathrm{H}_{3}\right)^{\prime \prime}$ as & 1492.6 & 7.5 & & 1457.6 & & & 1449.9 & \\
\hline$\delta\left(\mathrm{C} 5-\mathrm{H}_{3}\right)^{\prime}$ as & 1489.5 & 7.9 & & 1454.0 & & & 1445.7 & \\
\hline$\delta\left(\mathrm{C} 9-\mathrm{H}_{3}\right) \mathrm{s}$ & 1468.8 & 0.3 & & 1446.8 & & & 1442.9 & \\
\hline$\delta\left(\mathrm{C} 5-\mathrm{H}_{3}\right) \mathrm{s}$ & 1459.0 & 0.4 & & 1428.9 & & & n.o. ${ }^{b}$ & \\
\hline$v(\mathrm{~S}=\mathrm{O})$ & 1206.0 & 150.0 & $1208.6 / 1207.0$ & & $\begin{array}{l}1211.7 / 1211.2 \\
1209.7\end{array}$ & 1203.3 & & $1206.5 / 1204.5$ \\
\hline$\gamma\left(\mathrm{C} 9-\mathrm{H}_{3}\right)^{\prime}$ & 1189.5 & 3.3 & & 1189.6 & & & 1194.4 & \\
\hline$\gamma\left(\mathrm{C} 5-\mathrm{H}_{3}\right)^{\prime}$ & 1183.3 & 5.1 & & 1187.9 & & 1185.8 & & 1182.6 \\
\hline$\gamma\left(\mathrm{C} 9-\mathrm{H}_{3}\right)^{\prime \prime}$ & 1175.9 & 2.8 & & n.o. ${ }^{b}$ & & & n.o. ${ }^{b}$ & \\
\hline$\gamma\left(\mathrm{C} 5-\mathrm{H}_{3}\right)^{\prime \prime}$ & 1168.7 & 1.9 & & n.o. ${ }^{b}$ & & & n.o. ${ }^{b}$ & \\
\hline$v(\mathrm{C} 9-\mathrm{O})$ & 1021.2 & 131.5 & 1016.6 & & $1018.8 / 1012.3$ & 1005.4 & & 1009.9/1007.6 \\
\hline$v(\mathrm{C} 5-\mathrm{O})$ & 982.7 & 249.1 & & 980.1 & & & 973.3 & \\
\hline$v(\mathrm{~S}-\mathrm{O} 2)$ & 727.5 & 86.2 & $748.3 / 747.3$ & & $750.1 / 746.9$ & 746.4 & & $747.5 / 744.9$ \\
\hline$v(\mathrm{~S}-\mathrm{O} 3)$ & 664.6 & 225.3 & 696.9 & & n.o. ${ }^{b}$ & 699.6 & & 692.7 \\
\hline$\gamma(\mathrm{S}=\mathrm{O})$ & 566.1 & 15.5 & & 578.2 & & & 580.0 & \\
\hline$\delta(\mathrm{S}=\mathrm{O})$ & 456.8 & 2.5 & & n.o. ${ }^{b}$ & & & n.o. ${ }^{b}$ & \\
\hline$\delta(\mathrm{OSO})$ & 383.8 & 5.7 & & n.o..$^{b}$ & & & n.o. ${ }^{b}$ & \\
\hline$\delta(\mathrm{S}-\mathrm{O} 2-\mathrm{C} 5)$ & 278.6 & 4.9 & & n.o. ${ }^{b}$ & & & n.o. ${ }^{b}$ & \\
\hline$\delta(\mathrm{S}-\mathrm{O} 3-\mathrm{C} 9)$ & 218.8 & 6.4 & & n.o. ${ }^{b}$ & & & n.o. ${ }^{b}$ & \\
\hline$\tau\left(\mathrm{C} 9-\mathrm{H}_{3}\right)$ & 141.6 & 4.2 & & n.i..$^{c}$ & & & n.i..$^{c}$ & \\
\hline$\tau\left(\mathrm{C} 5-\mathrm{H}_{3}\right)$ & 121.7 & 2.5 & & n.i..$^{c}$ & & & n.i..$^{c}$ & \\
\hline$\tau(\mathrm{S}-\mathrm{O} 2)$ & 93.2 & 4.3 & & n.i..$^{c}$ & & & n.i..$^{c}$ & \\
\hline$\tau(\mathrm{S}-\mathrm{O} 3)$ & 72.8 & 3.4 & & n.i. ${ }^{c}$ & & & n.i. ${ }^{c}$ & \\
\hline
\end{tabular}

${ }^{a} v$, bond stretching, $\delta$, bending, $\gamma$, rocking, $\tau$, torsion, s, symmetric, as, antisymmetric. See Table S02 of the Supporting Information for definitions of internal coordinates. ${ }^{b}$ Not observed. ${ }^{c}$ Not investigated.

the $\mathrm{GG}^{\prime} \rightarrow \mathrm{GT}$ energy barrier for the process involving this $\mathrm{GG}^{\prime}$ site is much higher than those associated with other $\mathrm{GG}^{\prime}$ sites, is not supported by the fact that the bands ascribed to this site start to decrease simultaneously (within our time resolution) with those assigned to the less stable $\mathrm{GG}^{\prime}$ sites.

The observations pointed out above regarding the $v(\mathrm{~S}=\mathrm{O})$ stretching region, where the bands due to the three conformers appear most well-separated, receive confirmation from the analysis of other spectral regions (see Figures 4 and 5). In the $v(\mathrm{C}-\mathrm{O})$ stretching region $\left(960-1030 \mathrm{~cm}^{-1}\right.$; Figure 4), each conformer is predicted to give rise to two bands. In the argon matrix spectrum, the less stable $\mathrm{GG}^{\prime}$ conformer gives rise to the bands 1165.8 and $1006.9 \mathrm{~cm}^{-1}$ (predicted at 1165.9 and $1007.3 \mathrm{~cm}^{-1}$, respectively), which systematically decrease upon annealing; conformer GT gives rise to the bands at 1016.6 and $1018.8 / 1012.3 \mathrm{~cm}^{-1}$, ascribed to the $v(\mathrm{C} 9-\mathrm{O})$ stretching mode in the more stable and less stable sites, respectively, and the broad feature centered at ca. $980 \mathrm{~cm}^{-1}$ (observed in the longer wavenumber wing of the $975.6 \mathrm{~cm}^{-1}$ band due to GG), which first increase in intensity $(15-21 \mathrm{~K})$ and then start to decrease; finally, the most stable GG form gives rise to the pairs of bands at 1009.7 (more stable site)/1009.2 (less stable site) $\mathrm{cm}^{-1}$ and 975.6 (less stable site)/972.1 (more stable site) $\mathrm{cm}^{-1}$, assigned to $v(\mathrm{C} 5-\mathrm{O})$ and $v(\mathrm{C} 9-\mathrm{O})$, respectively, that, as expected, start to grow for $T>21 \mathrm{~K}$. Note that the intensity changes in both the $980 \mathrm{~cm}^{-1}$ broad feature due to GT and the $975.6 \mathrm{~cm}^{-1}$ band of GG, though following the general expected behavior, are complicated by their extensive overlap. In the $660-750 \mathrm{~cm}^{-1}$ spectral range $(\gamma(\mathrm{S}=\mathrm{O}) ; \nu(\mathrm{S}-\mathrm{O}))$ depicted in Figure 5 the same pattern of variation of the band intensities described for the $1190-1240$ and $960-1030 \mathrm{~cm}^{-1}$ regions discussed above is observed. However, this spectral region is more complex due to extensive site splitting and, in the case of the lower frequency region $\left(660-700 \mathrm{~cm}^{-1}\right)$, also due to band splitting due to Fermi resonance interactions, which are particularly important for the $v(\mathrm{~S}-\mathrm{O} 2)$ band of the most stable conformer (see Figure 5). In this spectral region, the bands due to GT are observed at ca. $750 \mathrm{~cm}^{-1}(v(\mathrm{~S}-\mathrm{O} 2)$; as a quartet, with the midfrequency bands associated with the most stable site) and at $696.9 \mathrm{~cm}^{-1}$ $(v(\mathrm{~S}-\mathrm{O} 3)$ : most stable site; the bands originated in the less stable sites are, with all probability, buried underneath the closely located intense bands due to GG; see Figure 5). The features due to the $v(\mathrm{~S}-\mathrm{O})$ symmetric stretching of $\mathrm{GG}^{\prime}$ are observed at 698.3 (more stable site) and 699.1 (less stable site) $\mathrm{cm}^{-1}$, overlapping the $v(\mathrm{~S}-\mathrm{O} 3)$ band of $\mathrm{GT}$, while the $v(\mathrm{~S}-\mathrm{O})$ asymmetric mode in the same conformer gives rise to the multiplet observed between 685 and $677 \mathrm{~cm}^{-1}$, which results from conjugation of site splitting and Fermi resonance interaction with the $\gamma(\mathrm{S}=\mathrm{O})+\tau\left(\mathrm{CH}_{3}\right)$ sym combination tone $\left(\gamma(\mathrm{S}=\mathrm{O})\right.$ and $\tau\left(\mathrm{CH}_{3}\right)$ fundamentals are predicted by the calculations to occur at 599.2 and $84.3 \mathrm{~cm}^{-1}$, respectively; see Table 4). In this spectral region, the most stable GG conformer gives rise to the bands at 733.3 and $730.8 \mathrm{~cm}^{-1}$, assigned to $\gamma(\mathrm{S}=\mathrm{O})$ in the most and less stable sites, respectively, and to the multicomponent feature in the $694-688 \mathrm{~cm}^{-1}$ region, due to $v(\mathrm{~S}-\mathrm{O} 2)$, split due to matrix-site effects and by participation in a Fermi resonance with the $\delta(\mathrm{OCO})+\delta(\mathrm{S}-\mathrm{O} 3-\mathrm{C} 9)$ 
TABLE 4: Observed Frequencies $\left(\mathrm{cm}^{-1}\right)$ for the GG' Form of Dimethyl Sulfite Monomer in Argon Matrix (B3LYP/ aug-cc-pVQZ calculated frequencies and intensities $\left(\mathrm{km} \mathrm{mol}^{-1}\right)$ are given for comparison $)^{a}$

\begin{tabular}{|c|c|c|c|c|c|}
\hline \multirow[b]{2}{*}{$\begin{array}{c}\text { approx } \\
\text { description }\end{array}$} & \multirow[b]{2}{*}{$\begin{array}{c}\text { calcd } \\
\text { frequency }\end{array}$} & \multirow[b]{2}{*}{$\begin{array}{c}\text { calcd } \\
\text { intensity }\end{array}$} & \multicolumn{3}{|c|}{$\begin{array}{l}\text { obsd freq } \\
\operatorname{Ar}(9 \mathrm{~K})\end{array}$} \\
\hline & & & $\begin{array}{c}\text { more } \\
\text { stable site }\end{array}$ & & $\begin{array}{c}\text { less } \\
\text { stable site }\end{array}$ \\
\hline$v\left(\mathrm{CH}_{3}\right)^{\prime}$ as $\mathrm{s}$ & 3138.0 & 3.4 & & 3028.0 & \\
\hline$v\left(\mathrm{CH}_{3}\right)^{\prime}$ as as & 3137.3 & 8.7 & & 3028.0 & \\
\hline$v\left(\mathrm{CH}_{3}\right)^{\prime \prime}{ }_{\text {as }} \mathrm{s}$ & 3116.3 & 12.8 & & 2986.0 & \\
\hline$v\left(\mathrm{CH}_{3}\right)^{\prime \prime}$ as as & 3113.5 & 25.1 & & 2986.0 & \\
\hline$v\left(\mathrm{CH}_{3}\right)_{\mathrm{s}} \mathrm{S}$ & 3041.4 & 62.3 & & 2960.5 & \\
\hline$v\left(\mathrm{CH}_{3}\right)_{\mathrm{s}}$ as & 3037.5 & 9.4 & & 2960.5 & \\
\hline$\delta\left(\mathrm{CH}_{3}\right)^{\prime}$ as $\mathrm{s}$ & 1508.9 & 2.9 & & 1469.1 & \\
\hline$\delta\left(\mathrm{CH}_{3}\right)^{\prime \prime}$ as $\mathrm{S}$ & 1501.5 & 9.4 & & 1460.5 & \\
\hline$\delta\left(\mathrm{CH}_{3}\right)^{\prime}$ as as & 1500.1 & 16.3 & & 1460.5 & \\
\hline$\delta\left(\mathrm{CH}_{3}\right)^{\prime \prime}$ as as & 1491.1 & 2.9 & & 1455.7 & \\
\hline$\delta\left(\mathrm{CH}_{3}\right)_{\mathrm{s}} \mathrm{s}$ & 1461.9 & 2.1 & & 1428.9 & \\
\hline$\delta\left(\mathrm{CH}_{3}\right)_{\mathrm{s}}$ as & 1454.8 & 0.3 & & 1422.7 & \\
\hline$v(\mathrm{~S}=\mathrm{O})$ & 1195.7 & 122.3 & 1197.7 & & 1202.9/1199.7 \\
\hline$\gamma\left(\mathrm{CH}_{3}\right)^{\prime}$ as & 1183.3 & 0.9 & & n.o. ${ }^{b}$ & \\
\hline$\gamma\left(\mathrm{CH}_{3}\right)^{\prime} \mathrm{s}$ & 1182.1 & 16.4 & & 1180.4 & \\
\hline$\gamma\left(\mathrm{CH}_{3}\right)^{\prime \prime}$ as & 1167.6 & 0.9 & & n.o. ${ }^{b}$ & \\
\hline$\gamma\left(\mathrm{CH}_{3}\right)^{\prime \prime} \mathrm{s}$ & 1165.9 & 4.9 & & 1165.8 & \\
\hline$v(\mathrm{C}-\mathrm{O}) \mathrm{s}$ & 1007.3 & 197.5 & & 1006.9 & \\
\hline$v(\mathrm{C}-\mathrm{O})^{\prime \prime}$ as & 973.2 & 160.0 & & 965.7 & \\
\hline$v(\mathrm{~S}-\mathrm{O}) \mathrm{s}$ & 679.7 & 79.8 & 698.3 & & 699.1 \\
\hline$v(\mathrm{~S}-\mathrm{O})^{\prime \prime}$ as & 651.2 & 266.7 & 682.2 & & $685.0 / 683.7 / 680.1 / 677.5$ \\
\hline$\gamma(\mathrm{S}=\mathrm{O})$ & 599.2 & 15.3 & & 615.3 & \\
\hline$\delta(\mathrm{S}=\mathrm{O})$ & 479.3 & 0.0 & & n.o. ${ }^{b}$ & \\
\hline$\delta(\mathrm{OSO})$ & 354.1 & 7.6 & & n.o. ${ }^{b}$ & \\
\hline$\delta(\mathrm{SOC})$ as & 273.5 & 12.5 & & n.o. ${ }^{b}$ & \\
\hline$\delta(\mathrm{SOC}) \mathrm{s}$ & 266.1 & 11.4 & & n.o. ${ }^{b}$ & \\
\hline$\tau\left(\mathrm{CH}_{3}\right)$ as & 144.2 & 1.8 & & n.i..$^{c}$ & \\
\hline$\tau(\mathrm{S}-\mathrm{O})$ as & 93.9 & 2.2 & & n.i. ${ }^{c}$ & \\
\hline$\tau\left(\mathrm{CH}_{3}\right) \mathrm{s}$ & 84.3 & 0.0 & & n.i. ${ }^{c}$ & \\
\hline$\tau(\mathrm{S}-\mathrm{O}) \mathrm{s}$ & 44.2 & 0.7 & & n.i. ${ }^{c}$ & \\
\hline
\end{tabular}

${ }^{a} \nu$, bond stretching, $\delta$, bending, $\gamma$, rocking, $\tau$, torsion, s, symmetric, as, antisymmetric. See Table S03 of the Supporting Information for definitions of internal coordinates. ${ }^{b}$ Not observed. ${ }^{c}$ Not investigated.

combination tone (whose fundamentals are predicted at 427.0 and $250.3 \mathrm{~cm}^{-1}$, respectively).

The spectra obtained for $\mathrm{DMSO}_{3}$ isolated in xenon matrices substantially differ from those obtained for the compound isolated in argon. As shown in Figures 3-5, in the spectra of the compound in xenon no signs of presence of the $\mathrm{GG}^{\prime}$ conformer can be seen (this is particularly evident in the $v(\mathrm{~S}=\mathrm{O})$ stretching region shown in Figure 3), even when the matrix was deposited at the lowest temperature achievable in our matrix-isolation setup ( $9 \mathrm{~K})$. Very interestingly, the intensity ratio of the bands due to the two conformers observed in xenon matrices (GG/GT) decreases when compared with the spectra obtained in argon (see Figure 3), becoming similar to the ratio of intensities $\mathrm{GG} /\left(\mathrm{GT}+\mathrm{GG}^{\prime}\right)$ observed in argon. [Note that the IR spectra of the three conformers of $\mathrm{DMSO}_{3}$ were also calculated using the PCM/SCRF approach in order to roughly estimate the band intensity changes due to change of matrix gas. In the two noble gases the calculated intensities suffer a general very small increase compared with vacuum, which was found to be identical in both gases. Moreover, the relative intensities of the bands due to the three conformers do not change by changing the media.] Hence, these results indicate that during deposition of the xenon matrices conformer $\mathrm{GG}^{\prime}$ totally converts to conformer GT, thus fully confirming the predictions made in the previous section, which took into consideration the low calculated energy barrier for the $\mathrm{GG}^{\prime} \rightarrow \mathrm{GT}$ isomerization process and the fact that xenon is an efficient matrix gas for observation of conformational cooling during matrix deposition. ${ }^{36}$

As in the case of the spectra of the compound in argon, the spectra of $\mathrm{DMSO}_{3}$ in xenon matrices do also show extensive site splitting. The assignment of the bands originated in mol- ecules in the most stable and less stable sites is provided in Tables 2-4. Also as in argon matrices, annealing of the xenon matrices lead to conversion of GT into the most stable GG conformer, though in this case the faster production of aggregates precludes a detailed study of the $\mathrm{GT} \rightarrow \mathrm{GG}$ isomerization.

A final note shall be made here regarding the relative stability of the conformers in the gaseous phase. Matrix isolation experiments can, in principle, be used in a simple way to investigate the relative stability of the conformers in the gas, by collecting spectra obtained using different nozzle temperatures. There are, however, a few conditions that must be verified in order to do so: first, conformational interconversion cannot take place during matrix deposition (so, in our case, the xenon experiments cannot help very much, at least in what is of concern to the relative stability of GT and $\mathrm{GG}^{\prime}$ in the gas phase); second, no conformational interconversion can occur in the matrix, i.e., the energy barriers for conformational interconversion cannot be so small that true conformational equilibrium can be achieved in the matrix (this condition is, for sure, verified in our case, since the intensity changes observed upon annealing were not found to be reversible upon lowering the temperature); and, finally, the population changes with the temperature of the nozzle must be large enough to lead to observable changes of relative band intensities.

For $\mathrm{DMSO}_{3}$, it can be easily estimated from the calculated relative conformational energies that increasing the temperature of the nozzle from 298 to $393 \mathrm{~K}$ (above this temperature the compound decomposes extensively) the populations of the GG/ GT/GG' conformers change from $48.8 \% / 35.0 \% / 15.1 \%$ to $45.8 \% /$ $35.5 \% / 15.9 \%$ (in these calculations, $\mathrm{G}^{\prime} \mathrm{T}$ and TT were also including, their joint populations being 1.1 and $2.8 \%$, respectively at 298 and $393 \mathrm{~K}$; see Table 1). The expected population 
changes are then predicted to be too small to allow a clear observation of population redistribution on the basis of band intensity changes, and, in fact, the results we obtained were inconclusive. On the other hand, the adequate description of conformational interconversions taking place in the matrices (both during deposition and upon annealing of the matrices), based on the theoretically predicted energetic data, appears as a strong indirect support pointing to the adequacy of the calculated potential energy profiles shown in Figure 2 also to describe the gaseous phase.

\section{Conclusion}

The conformational analysis of $\mathrm{DMSO}_{3}$ was carried out. The potential energy surface was investigated at different levels of theory, including the MP2/6-31++G(d,p) and DFT(B3LYP)/ aug-cc-pVQZ high-level approximations. Among the five different minima found in the potential energy surface of $\mathrm{DMSO}_{3}$, conformer GG, which is analogous to the conformational ground state of $\mathrm{DMSO}_{4},{ }^{13}$ was predicted to be the most stable conformer, whereas GT and $\mathrm{GG}^{\prime}$ result the second and third most stable conformers, with energies of 0.83 and $1.18 \mathrm{~kJ} \mathrm{~mol}^{-1}$ higher than the most stable form. The remaining two conformers are predicted to have relative energies of more than ca. $10 \mathrm{~kJ}$ $\mathrm{mol}^{-1}$ and not relevant in practical terms.

In argon matrices, the three most stable conformers of $\mathrm{DMSO}_{3}\left(\mathrm{GG}, \mathrm{GG}^{\prime}\right.$, and GT) could be isolated and characterized spectroscopically for the first time. Annealing of the argon matrices first promotes the $\mathrm{GG}^{\prime} \rightarrow \mathrm{GT}$ isomerization, which is followed by conversion of GT into the most stable conformer. On the other hand, there is no evidence of occurrence of the $\mathrm{GG}^{\prime} \rightarrow \mathrm{GG}$ direct conversion in the low-temperature argon matrices. These results could be explained taking into account the relative values of the theoretically predicted energy barriers for the different isomerization processes: $\mathrm{GG}^{\prime} \rightarrow \mathrm{GT}, 1.90 \mathrm{~kJ}$ $\mathrm{mol}^{-1}$; GT $\rightarrow \mathrm{GG}, 9.64 \mathrm{~kJ} \mathrm{~mol}^{-1}$; and $\mathrm{GG}^{\prime} \rightarrow \mathrm{GG}, 19.46 \mathrm{~kJ} \mathrm{~mol}^{-1}$.

In the xenon matrices, only the GG and GT conformers were observed, since during deposition the $\mathrm{GG}^{\prime}$ conformer totally converts to GT, which is trapped with a population nearly equal to the sum of the GT and $\mathrm{GG}^{\prime}$ populations found in the argon matrices (this result is a further evidence of the non occurrence of direct $\mathrm{GG}^{\prime} \rightarrow \mathrm{GG}$ isomerization under the experimental conditions here used).

Acknowledgment. This work was supported by the Portuguese Fundação para a Ciência e a Tecnologia (FCT) and FEDER. A.G.-Z. also appreciates the Grant SFRH/BPD/11499/ 2002 from FCT, CONICET, and the Argentinian Agencia Nacional de Promoción Científica y Tecnológica (PICT 13080).

Supporting Information Available: Table S01, listing optimized geometries for the conformers of $\mathrm{DMSO}_{3}$, Tables $\mathrm{S} 02$ and S03, giving definitions of internal coordinates for both $C_{1}$ and $C_{\mathrm{s}}$ symmetry point group conformers of $\mathrm{DMSO}_{3}$, and Tables S4-S8, showing calculated vibrational spectra and normal coordinate analysis for the five conformers of $\mathrm{DMSO}_{3}$. This material is available free of charge via the Internet at http:// pubs.acs.org.

\section{References and Notes}

(1) Woerden, H. Chem. Rev. 1963, 63, 557.

(2) Gawienowski, A.; Stacewicz-Sapuntzakis, M. Behav. Biol. 1978, 23, 267.

(3) Carre, P.; Libermann, D. Bull. Soc. Chim. 1933, 1050.

(4) Berti, G. J. Am. Chem. Soc. 1954, 76, 1213.

(5) Grabowski, J.; Lumin, R. J. Am. Chem. Soc. 1990, 112, 607.

(6) Klaeboe, P. Acta Chem. Scand. 1968, 22, 2817.

(7) Huong, P. V.; Raducanu, E. J. Mol. Struct. 1974, 23, 81.

(8) Cazaux, L.; Bastide, J. D.; Chassaing, G.; Maroni, P. Spectrochim. Acta A 1979, 35, 15.

(9) Cazaux, L.; Chassaing, G.; Maroni, P. Spectrochim. Acta A 1984, 40,519 .

(10) Remizov, A. B.; Fishman, A. I.; Pominov, I. S. Spectrochim. Acta A 1979, 35, 901.

(11) Odeurs, R. L.; Van der Veken, B. J.; Herman, M. A. J. Mol. Struct 1982, 79, 451.

(12) Zeng, A.; Yu, L.; Wang, Y.; Kong, Q.; Xu, Q.; Zhou, M. J. Phys. Chem. A 2004, 108, 6656.

(13) Borba, A.; Gómez-Zavaglia, A.; Simões, P. N. N. L.; Fausto, R. Spectrochim. Acta A, in press (doi: 10.1016).

(14) Reva, I.; Stepanian, S.; Adamowicz, L.; Fausto, R. J. Phys. Chem. A 2001, 105, 4773.

(15) Frisch, M. J.; Trucks, G. W.; Schlegel, H. B.; Scuseria, G. E.; Robb, M. A.; Cheeseman, J. R.; Zakrzewski, V. G.; Montgomery, J. A., Jr.; Stratmann, R. E.; Burant, J. C.; Dapprich, S.; Millam, J. M.; Daniels, A. D.; Kudin, K. N.; Strain, M. C.; Farkas, O.; Tomasi, J.; Barone, V.; Cossi, M.; Cammi, R.; Mennucci, B.; Pomelli, C.; Adamo, C.; Clifford, S.; Ochterski, J.; Petersson, G. A.; Ayala, P. Y.; Cui, Q.; Morokuma, K.; Malick, D. K.; Rabuck, A. D.; Raghavachari, K.; Foresman, J. B.; Cioslowski, J.; Ortiz, J. V.; Baboul, A. G.; Stefanov, B. B.; Liu, G.; Liashenko, A.; Piskorz, P.; Komaromi, I.; Gomperts, R.; Martin, R. L.; Fox, D. J.; Keith, T.; AlLaham, M. A.; Peng, C. Y.; Nanayakkara, A.; Gonzalez, C.; Challacombe, M.; Gill, P. M. W.; Johnson, B.; Chen, W.; Wong, M. W.; Andres, J. L.; Gonzalez, C.; Head-Gordon, M.; Replogle, E. S.; Pople, J. A. Gaussian 98, Revision A.9; Gaussian, Inc.: Pittsburgh, PA 1998.

(16) McLean, A. D.; Chandler, G. S. J. Chem. Phys, 1980, 72, 5639.

(17) Krishnan, R. Binkley, J. S.; Seeger, R.; Pople, J. A. J. Chem. Phys. 1980, 72,650 .

(18) Ditchfield, R.; Hehre, W. J.; Pople, J. A. J. Chem. Phys. 1971, $54,724$.

(19) Hehre, W. J.; Ditchfield, R.; Pople, J. A. J. Chem. Phys. 1972, $56,2257$.

(20) Dunning, T. H., Jr. J. Chem. Phys. 1989, 90, 1007.

(21) Clark, T.; Chandrasekhar, J.; Spitznagel, G. W.; Schleyer, P. v. R. J. Comput. Chem. 1983, 4, 294.

(22) Woon, D. E.; Dunning, T. H., Jr. J. Chem. Phys. 1993, 98, 1358

(23) Kendall, R. A.; Dunning, T. H., Jr.; Harrison, R. J. J. Chem. Phys. 1992, 96, 6796.

(24) Moller, C.; Plesset, M. S. Phys. Rev. 1934, 46, 618.

(25) Frisch, M.; Head-Gordon, M.; Pople, J. A. Chem. Phys. Lett. 1990, 166, 281.

(26) Becke, A. Phys. Rev. A 1988, 38, 3098.

(27) Lee, C.; Yang, W.; Parr, R. Phys. Rev. B 1988, 37, 785.

(28) Csaszar, P.; Pulay, P. THEOCHEM 1984, 114, 31.

(29) Peng, C.; Schlegel, H. B. Isr. J. Chem. 1994, 33, 449.

(30) Mennucci, B.; Tomasi, J. J. Chem. Phys. 1997, 106, 5151.

(31) Mennucci, B.; Cancès, E.; Tomasi, J. J. Phys. Chem. B 1997, 101, 10506.

(32) Cammi, R.; Mennucci, B.; Tomasi, J. J. Phys. Chem. A 2000, 104, 5631.

(33) Schachtschneider, J. Technical Report; Shell Development Co.: Emeryville, CA, 1969.

(34) Barnes, A. J. J. Mol. Struct. 1984, 113, 161.

(35) Gómez-Zavaglia, A.; Fausto, R. Phys. Chem. Chem. Phys. 2003, 5,52 .

(36) Reva, I. D.; Stepanian, S. G.; Adamowicz, L.; Fausto, R. Chem. Phys. Lett. 2003, 374, 361. 